\title{
Interpretación de mecanismos de difusión del sistema de seguro de Depósitos en el Sistema Financiero Popular y Solidario
}

\section{Interpretation of mechanisms to disseminate the deposit insurance system in the Popular and Solidarity financial system}

\author{
Alex Giovanny Ipiales Poveda \\ alexbsc1987@hotmail.com \\ abgalexipiales@gmail.com \\ Laura Consuelo Baque \\ laurybaque@outlook.com \\ Universidad Central del Ecuador, Ecuador
}

Recibido octubre 2018; arbitrado noviembre 2018; y publicado enero 2019

\begin{abstract}
RESUMEN
A lo largo de la vida republicana del Ecuador, el país ha sufrido múltiples crisis económicas ocasionadas por el sistema financiero nacional, una de ellas es la ocurrida el 08 de marzo de 1999. El objetivo principal de este estudio fue implementar un mecanismo de difusión, respecto del Sistema de Seguro de Depósitos en el Sistema Financiero Popular y Solidario, a fin de orientar a los depositantes de las Cooperativas de Ahorro y Crédito, sobre una cultura financiera adecuada de sus recursos. Es una investigación cualitativa y cuantitativa, se encarga de establecer y conocer el origen de la falta de cultura financiera en los depositantes del sector financiero Popular y la forma que repercute este accionar, cuando una Institución financiera es declarada en liquidación forzosa por el organismo de control. Para finalizar Se debe determinar que la propia ciudadanía debe exigir por su propio bienestar económico que el Estado sea el precursor de socializar el Seguro de Depósitos como parte integral de la Red de Seguridad Financiera en el Ecuador.
\end{abstract}

Palabras clave: Seguro de depósitos; Sistema financiero popular y solidario; difusión
ABSTRACT

Throughout the Republican life of Ecuador, the country has suffered multiple economic crises caused by the national financial system, one of them is that occurred on March 8, 1999. The main objective of this study was to implement a diffusion mechanism, with regard to the deposit insurance system in the Popular and solidarity financial system, in order to guide the depositors of the credit unions, on a culture adequate financial resources. It is a qualitative and quantitative research, it is in charge of establishing and knowing the origin of the lack of financial culture in the depositors of the popular financial sector and the form that affects this action, when a financial institution is declared in Compulsory liquidation by the supervisory body. Finally, it must be determined that the citizenship itself must demand for its own economic well-being that the state is the forerunner of socializing deposit insurance as an integral part of the financial safety net in Ecuador.

Key words: Deposit insurance; Popular and solidary financial system; diffusion 


\section{INTRODUCCIÓN}

A lo largo de la vida republicana del Ecuador, el país ha sufrido múltiples crisis económicas ocasionadas por el sistema financiero nacional, una de ellas y que quizá ha generado mayor impacto social es la ocurrida el 08 de marzo de 1999 fecha en la cual el presidente del Ecuador Jamil Mahuad Witt, decreto un congelamiento de depósitos que dio lugar al denominado "Feriado Bancario", que consecuentemente desencadenó un colapso del sistema financiero ecuatoriano, ya que hubo muchas Instituciones financieras que fueron declaradas inviables y en quiebra como es el caso de Filanbanco, Banco Popular, Banco de Préstamos, Bancomex, Solbanco, Banco Continental entre otros, instituciones financieras que concentraban más del $50 \%$ de los depósitos de los ciudadanos ecuatorianos y extranjeros en el Ecuador.

En ese contexto, el Estado se constituyó en garantista de los depósitos que los ciudadanos mantenía en las instituciones financieras declaradas inviables, es decir de los cuenta ahorristas y cuenta correntistas de los mencionados bancos, todo a través de la denominada LEY TROLE I (Ley de Reordenamiento en materia Económica Tributario Financiera) que creó la "Agencia de Garantía de Depósitos”, entidad pública cuyo nombre denotaba protección a los depositantes, aunque en realidad, solo serviría para encargar al Estado la obligación de asumir las obligaciones de una banca que se derrumbaba por la insolvencia; y que "aseguraba" los depósitos de una manera ortodoxa, poco técnica y sin límite de cobertura, esto significó que la AGD no pueda asumir todas las obligaciones de los depositantes del sistema financiero ecuatoriano, lo que género que la ciudadanía tenga poca credibilidad en la Banca Nacional y prefiera guardar sus ahorros en sus casas y no en una institución financiera. (Keynes, 2014)
El 09 de marzo de 2000, el Ecuador adoptó el Dólar de los Estados Unidos de América como moneda oficial de curso legal en reemplazo del SUCRE, hecho que ha generado cierta estabilidad monetaria hasta la actualidad; y consecuentemente un equilibrio macroeconómico.

El 23 de enero de 2001, el Congreso Nacional expidió la Codificación de la Ley Orgánica de Instituciones del Sistema Financiero, como medida para restablecer la supervisión y tomar el control del Sistema Financiero a fin de generar confianza en la ciudadanía.

El 31 de Diciembre de 2008, luego de la falta de prolijidad en el control, supervisión y vigilancia del sistema financiero por parte de los organismos de control, se expide la "Ley de Creación de la Seguridad de la red de Seguridad Financiera", cuerpo jurídico que tiene como objeto y finalidad restablecer la confianza en las instituciones financieras, reducir los riesgos sistémicos de quiebra y principalmente precautelar el interés de los depositantes, denotando la clara intención del Gobierno de generar, una vez más en la ciudadanía, la confianza en las instituciones financieras del país.

Con el referido marco normativo se establecieron cuatro pilares fundamentales que estructuran la red de seguridad financiera del país, que a saber son: la Supervisión Bancaria, Fondo de Liquidez del Sistema Financiero, Esquema de Resolución Bancaria; y el Seguro de Depósitos, siendo este último la institución jurídica materia de la presente investigación.

Este estudio tuvo como principal objetivo Diseñar e implementar un mecanismo de difusión, respecto del Sistema de Seguro de Depósitos en el Sistema Financiero Popular y Solidario, a fin de orientar a los depositantes de las Cooperativas de Ahorro y Crédito, sobre una cultura financiera adecuada de sus recursos. 
La finalidad de este articulo radica en coadyuvar a la confianza en el sistema financiero partiendo del principio fundamental de la cultura financiera ciudadana y de la existencia in situ del Seguro de Depósitos, en el cual se abordarán datos históricos, procesos evolutivos del Seguro de Depósitos en el Ecuador, el fortalecimiento del sistema de Economía Popular y Solidaria y su intrínseca relación con el sistema financiero ecuatoriano, se describe la problemática y las posibles soluciones para la optimización del sistema de Seguro de Depósitos enfocado al sector financiero de la Economía Popular y Solidaria.

\section{Importancia de la Problemática}

Existe un alto nivel de desconocimiento de la sociedad en general, sobre la GESTIÓN y el PROCEDIMIENTO que se realiza cuando una Cooperativa de Ahorro y Crédito es declarada en Liquidación Forzosa por el Organismo de Control, hasta cuando el ciudadano recupera el depósito entregado a la Cooperativa que se liquidó, tomando en cuenta el rol protagónico que realiza la Corporación del Seguro de Depósitos en el sector de economía Popular y Solidaria; lo cual va acompañado de varios vacíos respecto de la cultura financiera y de la existencia del Seguro de Depósitos.

Después del feriado bancario en el Ecuador, hecho que generó un caos en la sociedad ecuatoriana y que repercutió principalmente en el sector de la economía, ocasionando un problema social irreversible como la emigración, la delincuencia, la violencia intrafamiliar, la desunión familiar; y su falta de cultura financiera respecto de asegurar sus depósitos en las entidades financieras del país ha ocasionado que en la actualidad incida en el comportamiento social cuando una institución financiera es declarada en liquidación forzosa, respecto de sus depositantes.

El desconocimiento que se produce en los depositantes del sector de economía popular y solidaria, respecto de la cobertura del Seguro que se da a sus depósitos, ha generado gran preocupación en la ciudadanía respecto de la devolución y el procedimiento que se realiza para dicha devolución, lo que constituye un problema social que conmociona el sector financiero popular y solidario.

Principalmente cuando una Cooperativa de ahorro y crédito ha sido declarada en liquidación forzosa, surge un problema social, ya que el común de los depositantes no sabe la forma en la cual recuperará sus depósitos, así como tampoco conocen el mecanismo gubernamental que se activa respecto de la devolución de sus depósitos.

Esto ha generado una desconfianza en el sistema financiero popular y solidario, ocasionando una incertidumbre social respecto de los depósitos que se han realizado en las cooperativas de ahorro y crédito, tomando en cuenta que son 830 de las cooperativas de ahorro y crédito que se encuentran actualmente en funcionamiento, todas bajo el control y supervisión del organismo de control como lo es Superintendencia de Economía Popular y Solidaria; a esto hay que sumar que actualmente se encuentran en proceso de liquidación 37 Cooperativas de Ahorro y crédito que potencialmente sus depositantes serán cubiertos por el Seguro de Depósitos; según datos detallados por el organismo de control; es decir la Superintendencia de Economía Popular y Solidaria..

Con estos antecedentes, es menester establecer el problema fundamental en los depositantes del sector financiero popular y solidario, sintetizando que la falta de una cultura financiera adecuada y coherente con el sistema financiero del sector, sumado al desconocimiento del Seguro de Depósitos y su procedimiento respecto a la devolución de sus depósitos, han generado una crisis social, principalmente de incertidumbre, inseguridad, desconfianza $y$ falta de credibilidad en el sistema cooperativo en el Ecuador, por lo que se busca mecanismos para el ciudadano conozca este sistema. 


\begin{abstract}
METODOLOGÍA
Esta investigación se ubica en una investigación de campo de carácter descriptivo, debido a que se encarga de describir el origen de la falta de cultura financiera en los depositantes del sector financiero Popular y Solidario y de qué forma repercute este accionar, cuando una Institución Financiera es declarada en Liquidación forzosa por el Organismo de Control a través de la impresiones de las personas involucradas y afectadas.

En síntesis, mediante el uso de este tipo de diseño permitirá con esta investigación interpretar las causas y efectos del objeto estudiado, la misma que también ayudará hacer un análisis de los posibles resultados, facilitando de esta manera obtener las mecanismos para obtener un fácil acceso al sistema de Seguro de Depósitos y lograr su socialización. Por otra parte haciendo relación, mediante la obtención de datos exactos en la investigación de campo permitió realizar un diagnóstico coherente, veras y eficaz, del sistema de Seguro de Depósitos en las Cooperativas de Ahorro y Crédito.
\end{abstract}

\section{RESULTADOS Y DISCUSIÓN}

Para el análisis de los resultados obtenidos de este estudio se aplicó un modelo de encuesta dirigida a los usuarios, depositantes, y representantes legales de las Cooperativas de Ahorro y Crédito en el Ecuador, para obtener sus impresiones con respecto al seguro de depósitos financiero popular y solidario. La encuesta estuvo diseñadas con 10 preguntas de selección simple y cerrada, para lograr con ella obtención de los datos que permitiese realizar un análisis descriptivo de la información. A continuación se presenta algunos ítems que dieron lugar al estudio.

\section{Acerca del conocimiento sobre el sistema Financiero Popular y Solidario}

En base a los datos recopilados se estableció que se debe dar a conocer más el sistema financiero Popular y Solidario, como sistema propiamente establecido, hay que anotar también que a la mayoría de encuestados desconocen cuando se habla de sistema financiero, pero sí reconocen cuando se pronuncia Cooperativa de Ahorro y Crédito, lo que demuestra la falta de socialización de este sistema financiero nacional.

De acuerdo a la encuesta realizada a los depositantes, usuarios y Representantes legales de las Cooperativas de Ahorro y Crédito el 52, 67\% de los encuestados manifiesta que si conocen el sistema financiero Popular y Solidario; mientras que el $47,33 \%$ de los encuestados manifiestan de que no conocen sobre el sistema Financiero Popular y Solidario (ver gráfico 1).

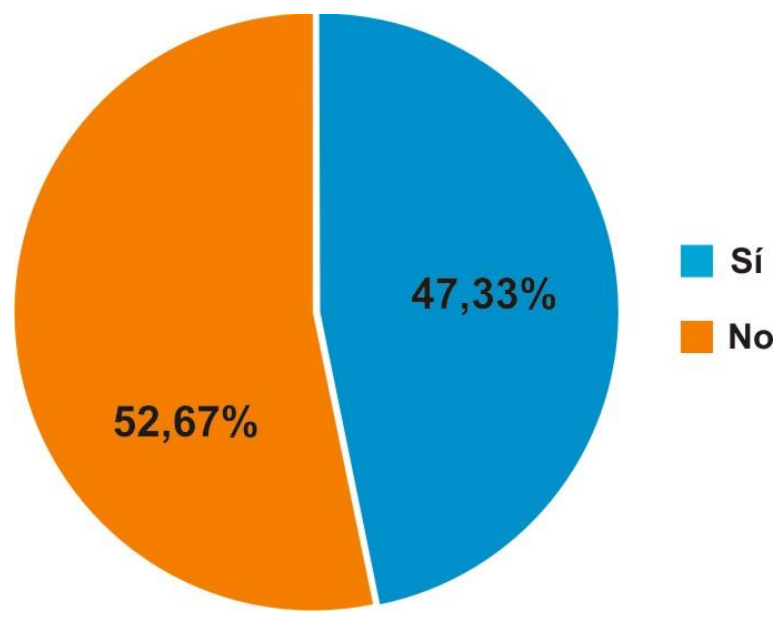

Gráfico 1. Conocimiento sobre el sistema Financiero Popular y Solidario.

\section{El sistema de Seguro de Depósitos}

En relación a los datos recopilados se estableció que se debe dar a conocer más el sistema de Seguro de Depósitos, como sistema propiamente establecido, hay que anotar también que a la mayoría de encuestados 
confunden el sistema de Seguro de Depósitos actual, con la gestión realizada por la extinta Agencia de Garantía de Depósitos (AGD), lo que demuestra la falta de socialización de este pilar dentro del sistema financiero nacional.

De acuerdo a la encuesta realizada a los depositantes, usuarios y Representantes legales de las entidades financieras del sector Popular y Solidario el $23,33 \%$ de los encuestados manifiesta que si conocen de alguna manera el sistema de Seguro de Depósitos; mientras que el 76,67\% de los encuestados manifiestan de que no conocen sobre el sistema de Seguro de Depósitos en el Ecuador (ver gráfico 2).

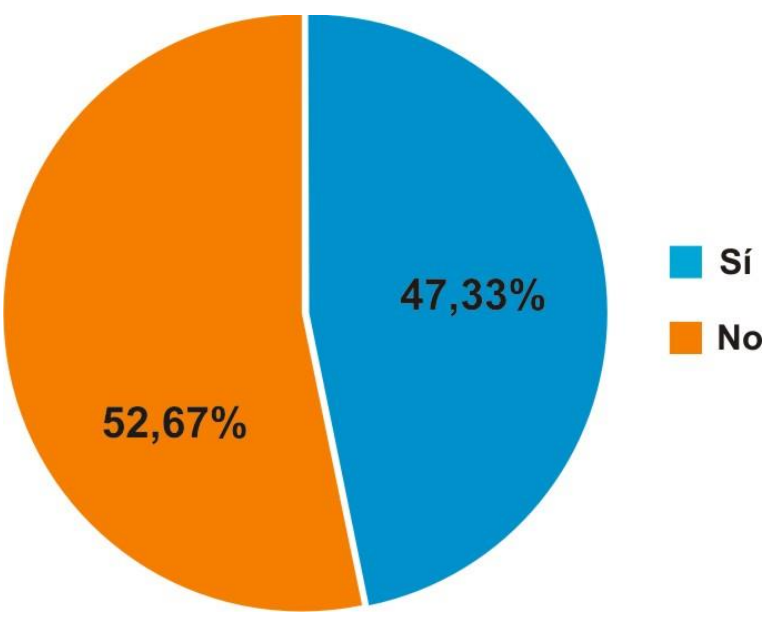

Gráfico 2. Conocimiento sobre el sistema de Seguro de Depósitos

\section{Las entidades financieras del sector popular y solidario y cuentan con un Seguro de Depósitos}

Es importante mencionar que se debe difundir y socializar de mejor manera el sistema de Seguro de Depósitos en el sector financiero Popular y Solidario, principalmente dentro del mismo sector como conocimiento para sus depositantes y usuarios, mayoritariamente conocían de este sistema los Representantes Legales de la entidades financieras encuestadas.

De acuerdo a la encuesta realizada a los depositantes, usuarios y Representantes legales de las entidades financieras del sector Popular y Solidario el 22\% de los encuestados manifiesta que si conocen de alguna manera que las entidades financieras del sector Popular y Solidario, cuentan con un Seguro de Depósitos; mientras que el $78 \%$ de los encuestados manifiestan de que no conocen que las entidades financieras del sector Popular y Solidario, cuentan con un Seguro de Depósitos en el Ecuador (ver gráfico 3).

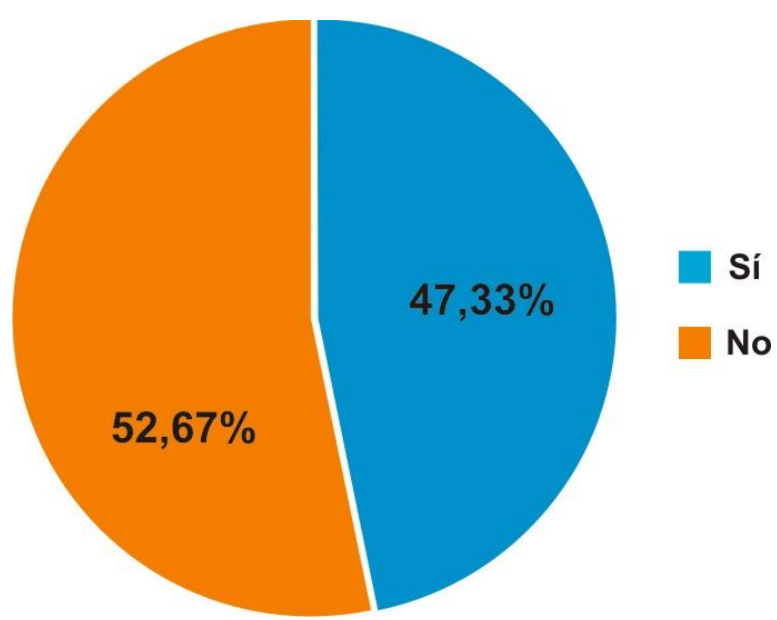

Grafico 3. Conocimiento las entidades financieras del sector popular y solidario y cuentan con un Seguro de Depósitos

\section{El Seguro de Depósitos contribuye en la confianza en el sistema financiero nacional}

En base a los datos recopilados se puede determinar que el sistema de Seguro de Depósitos contribuye para generar confianza en los depositantes y consecuentemente a generar confianza por parte de la ciudadanía en el sistema financiero nacional, hay que anotar algo importante los Representantes Legales ven al Seguro de Depósitos como un gasto, más no como una inversión de la Cooperativa de Ahorro y Crédito, ya que creen que el sistema económico no necesito ningún tipo de seguro.

De acuerdo a la encuesta realizada a los depositantes, usuarios y Representantes legales de las entidades financieras del sector 
Popular y Solidario el $72,67 \%$ de los encuestados manifiesta que si considera que el Seguro de Depósitos contribuye a la confianza en el sistema financiero nacional; mientras que el $27.33 \%$ de los encuestados manifiestan de que no considera que el Seguro de Depósitos contribuye a la confianza en el sistema financiero nacional en el Ecuador (ver gráfico 4).

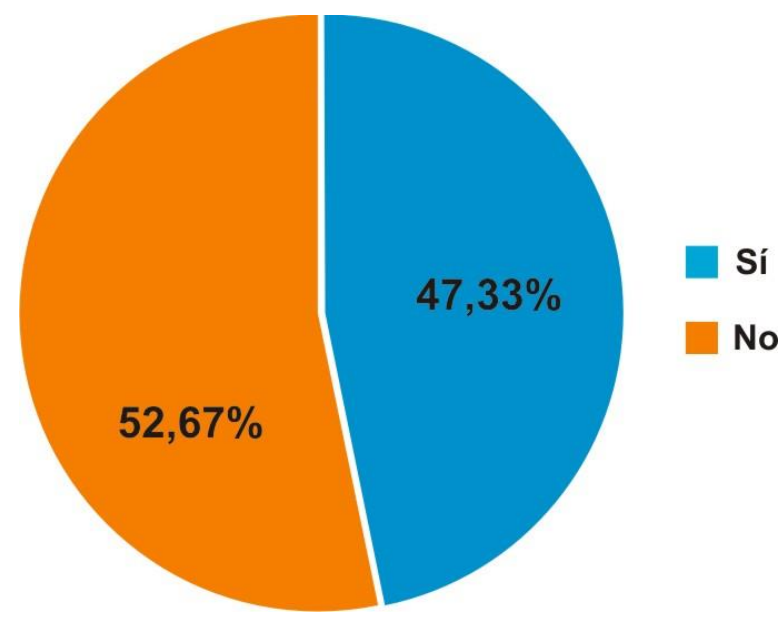

Gráfico 4. El Seguro de Depósitos contribuye a la confianza en el sistema financiero nacional

\section{Crédito}

En base a los datos recopilados se puede determinar que el Seguro de Depósitos si influye de cierta manera en los depositantes, aunque hay que tomar en cuenta que la mayoría de los encuestados no conoce de una manera prolija, clara y oportuna todo el andamiaje que gira a través del sistema de Seguro de Depósitos en el Ecuador.

De acuerdo a la encuesta que se muestra en el gráfico 5 realizada a los depositantes, usuarios y Representantes legales de las entidades financieras del sector Popular y Solidario el $22,67 \%$ de los encuestados considera que el Seguro de Depósitos repercute en el depositante de la Cooperativa de Ahorro y Crédito de una muy buena manera; el 58\% considera que repercute de una Buena manera el sistema de Seguro de Depósitos; el 16\% considera que el Seguro de Depósitos repercute en el depositante de la Cooperativa de Ahorro y Crédito de una manera regular; y el 3,33\% considera que el Seguro de Depósitos repercute en el depositante de la Cooperativa de Ahorro y Crédito de una mala manera.

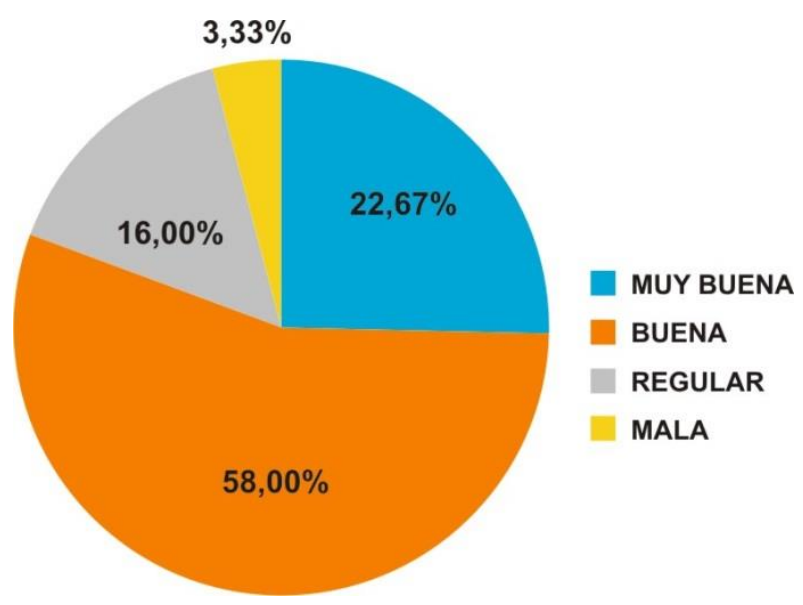

Gráfico 5. El Seguro de Depósitos repercute en el depositante de la Cooperativa de Ahorro y Crédito

\section{Depósitos asegurados de los ciudadanos en el sistema Popular y Solidario, durante el año 2015}

En base a los datos recopilados se puede establecer que la mayoría de los encuestados piensa que los depósitos durante el año 2015 se mantendrán igual que el año 2014, es decir mantendrán en promedio una similitud, esto se debe a que la equidad que existe dentro de los socios y depositantes del sector financiero Popular y Solidario es importante para la viabilidad financiera de este sector, básicamente se debe a que todos los socios son homogéneos y confían en el cooperativismo como medio de impulso social.

De acuerdo a la encuesta realizada a los depositantes, usuarios y Representantes legales de las entidades financieras del sector 
Popular y Solidario el 22,67\% cree que los depósitos asegurados de los ciudadanos en el sistema Popular y Solidario, durante el año 2015 aumentarán; el 58\% de los encuestados cree que se mantendrán igual; el $16 \%$ cree que aumentarán; mientras que el 3,33\% de los encuestados manifestó ninguno de los anteriores.

\section{CONCLUSIONES}

Luego de haber realizado la encuesta a los diferentes actores del sistema Financiero Popular y Solidario; y seguidamente efectuar el análisis e interpretación de los datos conseguidos, en este sentido según las muestra de los resultados obtenidos llego a las siguientes conclusiones:

La falta de información respecto del sistema de Seguro de Depósitos en el sistema Financiero Popular y Solidario, es un problema social que con lleva a los depositantes a tomar decisiones erradas respecto del manejo de su capital económico y su forma de inversión.

Sin embargo también hay que tomar en cuenta, que no solo es cuestión de los depositantes establecer una cultura financiera adecuada, para manejar su dinero, sino también de las Cooperativas de Ahorro y Crédito asesorar a sus socios respecto de la diversificación del riesgo en el capital.

Se ha determinado que la poca socialización, difusión e información que maneja el depositantes respecto del funcionamiento del sistema de Seguro de Depósitos, ha generado incertidumbre respecto de la liquidez de los dineros depositados en las Cooperativas de Ahorro y Crédito.

Se debe focalizar en los Organismos de Control la imperativa misión de difundir dentro de la ciudadanía en general, la gran importancia de contar con un sistema de Seguro de Depósitos, ágil, eficiente y oportuno, para de esta manera generar confianza en el sistema financiero nacional.
Se debe determinar que la propia ciudadanía debe exigir por su propio bienestar económico que el Estado sea el precursor de socializar el Seguro de Depósitos como parte integral de la Red de Seguridad Financiera en el Ecuador.

Es necesario implementar nuevos mecanismos de información para que los depositantes pueden tener de una manera fácil y veraz, el mayor conocimiento posible respecto del sistema de Seguro de Depósitos.

Es importante establecer medios de difusión con depositantes y usuarios de las Cooperativas de Ahorro y Crédito, con el fin de darles mayores herramientas para que puedan generar una cultura financiera adecuada a la realidad del sector financiero Popular y Solidario.

Es necesario la elaboración de un método de fácil socialización para establecer de forma clara y precisa el sistema de Seguro de Depósitos en las Cooperativas de Ahorro y Crédito, para que el depositante pueda establecer la diversificación del riesgo respecto de su capital de una manera adecuada y oportuna.

Es indispensable la difusión de las gestiones que realiza la COSEDE (2016), entidad estatal encargada de velar por el sistema de Seguro de Depósitos en el Ecuador, ya que en la actualidad se desconoce su misión dentro del sistema financiero nacional.

\section{REFERENCIAS}

Keynes, J. M. (2014). Teoría general de la ocupación, el interés y el dinero. Fondo de cultura económica, México

\section{Normativa Legal}

Codificación LGIF. (2001). Ley general de instituciones financieras. Quito. Ediciones Legales.

COSEDE-DIR-2016-001. (2016). Reglamento de Gestión del Seguro de Depósitos de los sectores financieros Privado y popular y Solidario. Quito. COSEDE. 
Interpretación de mecanismos de difusión del sistema de seguro de Depósitos en el Sistema Financiero Popular y Solidario

LEY DE CREACION DE LA RED DE SEGURIDAD FINANCIERA Ley 0 Registro Oficial Suplemento 498 de 31-dic-2008 Ultima modificación: 10-may-2011 Estado: Vigente

Superintendencia de Bancos y Seguros del Ecuador. (2011). Comportamiento del Sistema de Cooperativas de Ahorro y Crédito. Quito. Dirección Nacional de Estudios.

Superintendencia de Bancos y Seguros del Ecuador. (2012). Análisis Financiero del Sistema de Cooperativas de Ahorro y Crédito. Quito. Dirección Nacional de Estudios e Información.
Superintendencia de Economía Popular y Solidaria. (2014). Análisis de la Económia Popular y Solidaria. Quito. Dirección Nacional SEPS. 